\title{
Stage IV Appendix Neuroendocrine Tumor AJCC v8
}

National Cancer Institute

\section{Source}

National Cancer Institute. Stage IV Appendix Neuroendocrine Tumor A/CC v8. NCI

Thesaurus. Code C135160.

Stage IV includes: (T1, N0, N1, M1); (T2, N0, N1, M1); (T3, N0, N1, M1); (T4, N0, N1, M1).

T1: Tumor measuring $2 \mathrm{~cm}$ or less in greatest dimension. T2: Tumor measuring more than $2 \mathrm{~cm}$ but less than or equal to $4 \mathrm{~cm}$. T3: Tumor measuring more than $4 \mathrm{~cm}$ or with subserosal invasion or involvement of the mesoappendix. T4: Tumor perforating the peritoneum or directly invading other adjacent organs or structures (excluding direct mural extension to adjacent subserosa of adjacent bowel), e.g., abdominal wall and skeletal muscle. N0: No regional lymph node metastasis. N1: Regional lymph node metastasis. M1: Distant metastasis. (AJCC 8th ed.) 